\title{
PROVIDENCIA, RACIONALIDAD Y LEY NATURAL EN EL ESTOICISMO
}

\author{
LAura LiLiana Gómez Espíndola* \\ doi:10.11144/Javeriana.uph31-63.prle
}

\begin{abstract}
RESUMEN
Los intérpretes y las fuentes mismas del estoicismo tienden a equiparar las nociones de providencia, racionalidad y ley natural. En contraste con esta tendencia, el objetivo de este artículo es hacer un análisis de dichas nociones con miras a delimitar cuál es el papel explicativo que los estoicos atribuían a cada una de ellas. Esto permitirá tener una mejor comprensión de la teoría estoica de la constitución del mundo y de las diferentes funciones que la mente divina desempeña en ella. Se argumentará que la providencia es una función vinculada a la voluntad divina y referente al objetivo buscado en la constitución del mundo. La racionalidad divina remite a las exigencias lógicas y causales que han de ser respetadas en dicha constitución. Y la noción de ley natural remite a un aspecto normativo de la naturaleza establecido por la recta razón divina.
\end{abstract}

Palabras clave: providencia; ley natural; destino; racionalidad cósmica; cosmogonía

\footnotetext{
*Universidad del Valle, Cali, Colombia.

RECIBIDO: 25.04.14

ACEPTADO: 20.05.14

DISPONIBLE EN LÍNEA: 02.12.14

Para citar este artículo: Gómez Espíndola, L.L. (2014). Providencia, racionalidad y ley natural en el estoicismo. Universitas Philosophica, 31(63), pp. 39-70, ISSN 0120-5323, ISSN en línea 2346-2426, doi: 10.11144/Javeriana.uph31-63.prle
} 


\title{
PROVIDENCE, RATIONALITY AND NATURAL LAW IN STOICISM
}

\author{
LAURA Liliana Gómez Espíndola
}

\begin{abstract}
Interpreters and even the sources of stoicism tend to equate the notions of providence, rationality and natural law. In contrast to this trend, the goal of this article is to analyze these notions in order to identify what is the explanatory role attributed by the Stoics to each one of them. This will provide a better understanding of the Stoic theory of the constitution of the world and the different roles played by the divine mind in it. I will defend that providence is a function of the divine will, related to the goal sought in the constitution of the world. The divine rationality refers to the logical and causal requirements to be observed in this constitution. And the notion of natural law refers to a normative aspect of nature established by the divine right reason.
\end{abstract}

Key words: providence; natural law; fate; cosmic rationality; cosmogony 
LA FILOSOFÍA HELENÍsTiCA SE VIO NUTRIDA por el contraste entre dos cosmovisiones opuestas. Los epicúreos sostenían que el cosmos es el resultado de la ciega y azarosa interacción de innumerables átomos y en esa medida consideraban que el mundo está libre de toda providencia, teleología e intrínseca bondad. Por su parte, los estoicos estimaban inadmisible que un mundo de tanta belleza y armonía como el nuestro pudiera ser explicado de esta manera. De acuerdo con ellos, creer esto sería tan absurdo como pretender que al lanzar incontables ejemplares de las letras del abecedario en un recipiente y revolverlas se produjera una obra literaria (Cicerón, Nat. Deo. 2.93 (L\&S 54M)) $)^{1}$. Del mismo modo - dicen- que al entrar en una casa, gimnasio o foro bien ordenado nos rehusaríamos a considerar que ellos fueron de tal modo dispuestos por el azar, así la sola contemplación de la más perfecta armonía, orden y belleza de los cielos y demás obras de la naturaleza nos obliga a creer que estos fueron establecidos por una mente que administra el universo (Cicerón, Nat. Deo. 2. 15 (L\&S 54C) y 2.75-76 (L\&S 54J)).

Al reflexionar sobre la organización del mundo y el papel asignado a la humanidad en el mismo, los estoicos fueron encontrándose con la necesidad de atribuir a la divinidad diferentes funciones en la configuración y administración de la naturaleza. Estas funciones fueron designadas por los estoicos con diferentes nombres y respondían, cada una de ellas, a una necesidad explicativa diferente. No obstante, al encontrar un fuerte vínculo entre ellas, las fuentes que reportan la doctrina estoica tienden en ocasiones a equiparar estas funciones diciendo que la providencia, el destino, la ley natural, la razón, la naturaleza, Zeus y la verdad, son todos idénticos. ${ }^{2}$ En correspondencia con esto, algunos intérpretes han entendido estos términos como meros sinónimos que remiten a una misma realidad. En contraste con

\footnotetext{
${ }^{1}$ Todas las traducciones de los textos clásicos que aquí se presentarán son mías. En la citación se señalará siempre en primer lugar el autor, seguido por el nombre de la obra y líneas en que se encuentra el pasaje de acuerdo con las abreviaturas canónicas del DGE (http://dge.cchs.csic.es/). Para facilitar la ubicación de estos pasajes al lector, se señalará entre paréntesis el lugar que ellos ocupan, si así lo hacen, en la colección de fragmentos de Long, A.A., \& Sedley, D.N. 1987, mediante la sigla L\&S y en la de Arnim, H.F.A. v. 1903, mediante la sigla SVF.

${ }^{2} \mathrm{Al}$ respecto véase: Theodoret, Graec. Aff. Cur. VI 14 p. 153 (SVF 1.176), DL 7.159 (SVF 2.937); Eusebio, Praep. ev. 15.14.2 (L\&S 46G); Estobeo, Ecl. 1.5.15. 21-23 (SVF 2.913, L\&S 55M); Plutarco, Stoic. Rep. 1050 a-b, Ps.; Plutarco, Placita 885b.
} 
este tipo de lectura, el propósito de este escrito es hacer un estudio de las nociones de providencia, racionalidad y ley natural con miras a delimitar cuál es el papel explicativo que los estoicos atribuían a cada una de ellas. Esto permitirá tener una mejor comprensión de la teoría estoica de la constitución del mundo y de las diferentes funciones que Dios desempeña en ella.

\section{La organización providente del mundo}

COMENCEMOS ESTE ANÁLISIS SEÑALANDO QUE la administración del mundo no es ejercida por Dios a la manera de una fuerza externa que tiene una injerencia en el mundo. Por el contrario, los estoicos consideraban que Dios y la materia son los principios intrínsecos de la realidad, eternamente interrelacionados y separables solo en el pensamiento. Dios es entendido por ellos como el principio activo de la naturaleza encargado de dar forma y movimiento a la materia, que a su vez es el principio pasivo del mundo, en sí mismo informe e inmóvil y dispuesto por completo al cambio (Calcidio, Tim. 293 $(\mathrm{L} \& \mathrm{~S} 44 \mathrm{E}))^{3}$. Con base en esta concepción, Dios es también descrito como la mente del mundo, mente que desempeña diferentes funciones de las que nos ocuparemos a lo largo de este escrito. Iniciemos con la función que es

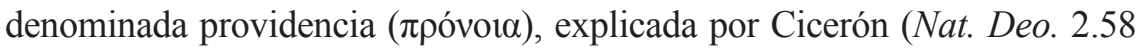
(L\&S 53Y y SVF 1.172)) en el siguiente pasaje:

[...] la naturaleza del mundo tiene todos los movimientos voluntarios, impulsos y deseos, que los griegos llaman ópuàs, y muestra de este modo acciones concordantes, de la manera como sucede con nosotros mismos que somos movidos por los propósitos y las sensaciones. Por lo tanto, siendo tal la mente del mundo, por esta causa puede rectamente ser llamada prudencia o si se quiere providencia (en griego, en efecto, es llamada $\pi \rho o ́ v o 1 \alpha)$, ésta procura lo más importante y se ocupa principalmente de esto: primero, que el mundo sea aptísimo para la supervivencia; luego, que no carezca de ninguna cosa, y principalmente, en fin, que haya en él una singular belleza y un ornato total. ${ }^{4}$

\footnotetext{
${ }^{3}$ Gourinat (2009) muestra cómo esto implica que los estoicos no pueden ser comprendidos como monistas materialistas (por no ser Dios un producto ulterior de la materia, sino un principio igualmente ingénito), ni como dualistas radicales (por ser finalmente los dos principios corpóreos y no de una naturaleza radicalmente distinta). Él propone que ellos deben ser comprendidos más bien como vitalistas (por ser Dios un principio racional que opera al interior de la materia).

4 "[...] natura mundi omnis motus habet voluntarios, conatusque et adpetitiones, quas ópù̀ Graeci vocant, et is consentaneas actiones sic adhibet ut nosmet ipsi qui animis
} 
De acuerdo con este testimonio, el motivo por el que la mente del mundo es llamada providencia es porque se ocupa de la producción de los movimientos del mundo de una manera semejante a como nosotros nos ocupamos de los movimientos de nuestro cuerpo. Así como nuestro cuerpo es movido en conformidad con los deseos e impulsos de nuestra mente, dándose el movimiento de los miembros con miras a alcanzar la finalidad que la mente ha trazado, de la misma manera los movimientos del mundo surgen a causa de los deseos e impulsos de Dios, y están dirigidos a alcanzar la finalidad que él ha trazado para el mundo. Por ello, los movimientos del mundo no son producidos por la mente de Dios sin un propósito, sino que están organizados con miras a alcanzar la finalidad deseada por él. Debido a esto los estoicos definen la providencia en términos de la voluntad de Dios

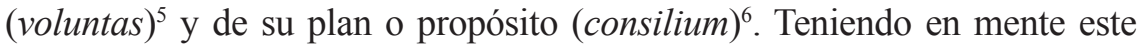
propósito, Dios procura (providet) las cosas necesarias para alcanzarlo, dirigiéndose a emprender los movimientos voluntarios necesarios que conducen a ello. El término providencia remite así a la finalidad deseada y perseguida por Dios a través de un plan que ejecuta en la administración del mundo.

De acuerdo con el pasaje de Cicerón que hemos citado, la finalidad con miras a la cual Dios genera los movimientos del mundo es la supervivencia, autosuficiencia y belleza total del mismo. Para lograr este propósito, la divinidad confiere a cada entidad un fin particular que contribuya a alcanzar el fin global del gran engranaje que es la naturaleza. Ahora bien, en esta configuración del mundo la divinidad estipula una jerarquía entre los seres naturales. Así, de acuerdo con los estoicos, el mundo entero fue creado con

\footnotetext{
movemur et sensibus. Talis igitur mens mundi cum sit ob eamque causam vel prudentia vel providentia appellari recte possit (Graece enim $\pi \rho$ óvola dicitur), haec potissimum providet et in is maxime est occupata, primum ut mundus quam aptissimus sit ad permanendum, deinde ut nulla re egeat, maxume autem ut in eo eximia pulchritudo sit atque omnis ornatus".

5 "Naturalmente la providencia será la voluntad de dios" / "Quippe providentiam dei fore voluntatem" (Calcidio, 144 (L\&S 54U y SVF 2.933)).

6 "Aseguro por lo tanto que es por la providencia de los dioses que el mundo y todas sus partes fueron al inicio creados y administrados por todos los tiempos [...] El mundo es gobernado por el plan de ellos" / "Dico igitur providentia deorum mundum et omnes mundi partes et initio constitutas esse et omni tempore administrari [...] est eorum consilio mundum administrari" (Cicerón, Nat. Deo. 2.75-76 (L\&S 54J)).
} 
miras al beneficio de los seres racionales: los humanos y los dioses ${ }^{7}$. Así, aunque cada naturaleza particular tenga un fin propio - ej. un árbol producir determinado fruto, un animal reproducirse y cuidar su descendencia- el beneficio de los seres racionales es un fin superior al que todos los demás están subordinados como medios. Los frutos fueron hechos con miras a los animales; los animales para que los hombres pudieran trasladarse, cubrirse y nutrirse; algunos animales y plantas incluso por mero ornato del mundo y disfrute de los hombres, pero los seres humanos no fueron hechos como medios para el provecho de otro ser de la naturaleza ${ }^{8}$. Por el contrario, el fin de los seres humanos está dirigido a su propio beneficio. Esto se ve reflejado en las tres descripciones del fin humano que se pueden rastrear en las

\footnotetext{
${ }^{7}$ Véase: Cicerón, Nat. Deo. II 133 (SVF. 2.1131, L\&S 54 N). Orígenes ilustra esta relación de subordinación con la siguiente analogía: los seres racionales ocupan en el mundo el mismo lugar que el niño ocupa en el vientre, mientras que las otras cosas animadas e inanimadas, el de la placenta. De este modo, afirma, la providencia ha organizado todo con miras al beneficio de los seres racionales, aunque concomitantemente los otros seres se vean beneficiados. Cf. Orígenes, Contra Celsum. IV 74 (SVF 2.1157). Por otra parte, los estoicos se esfuerzan en explicar cómo el ser humano, a pesar de parecer el ser más desfavorecido de la naturaleza (por ser más débil, lento y frágil que los otros animales), se puede comprender como señor de esta, gracias a que con su razón puede dominar a todos los seres que hacen parte de ella. Cf. Séneca, De Beneficiis. II. 29 (SVF 2.1121). Para ampliar la idea del hombre como beneficiario último de la administración providente de la naturaleza ver SVF 2. 1152-1167.

${ }^{8}$ En este punto vale la pena remitir al cuidadoso estudio de la jerarquía teleológica de los estoicos realizada por Salles, que le permite explicitar los principios sobre los que esta se fundamenta y cómo de ellos se sigue que el humano es superior a los demás seres de la naturaleza y que, a su vez, "el cosmos en su conjunto es superior al hombre". Este análisis lleva a Salles a afirmar que la teleología estoica no es antropocentrista, sino más bien cosmocentrista. Al analizar un pasaje de Eusebio en el que afirma que el cosmos ha de ser entendido como el hogar de dioses y hombres, en el que todo lo demás está puesto para el beneficio de ellos y en el que los dioses se han de entender como gobernantes de los hombres, Salles concluye que este pasaje defiende una lectura teocentrista de la teleología estoica. No obstante, recordando la identidad que los estoicos establecen entre el dios y el cosmos, Salles menciona que el teocentrismo no contradice al cosmocentrismo (Salles, 2013, pp. 59-62). Ahora bien, aunque es cierto que algunos pasajes intentan sugerir que el hombre está teleológicamente subordinado al cosmos (Cicerón, Nat. Deo. 2.37-38), hay otros pasajes que sugieren que la constitución misma del mundo y de todo lo que hay en él fue establecida con miras a los seres dotados de razón (Cicerón, Nat. Deo. II 133 y pasajes citados en la nota 8). No encontramos por el momento razones definitivas para favorecer una interpretación cosmocentrista o una antropocentrista, por ello nos limitamos en este texto a señalar no la relación teleológica entre el humano y el cosmos, sino la que hay entre el humano y todas las demás partes de la naturaleza. En conjunción con esto nos permitimos subrayar también que el hombre no ha de ser concebido como un puro medio, puesto que el fin del hombre está dirigido a su propio beneficio.
} 
fuentes: (i) vivir virtuosamente', (ii) contemplar e imitar el mundo (Cicerón, Nat. Deo. (L\&S 54H, SVF 2.1153)) y (iii) establecer una comunidad entre humanos y dioses ${ }^{10}$.

Para lograr la finalidad deseada, la divinidad conforma a cada ser desde su génesis y lo dota de unas inclinaciones que favorecen la consecución de su fin propio y del fin común. Esto sucede a través de algo que los estoicos

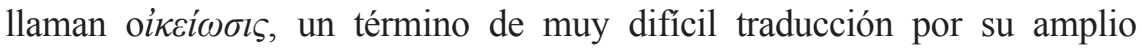
contenido semántico. El verbo del que proviene este sustantivo (oíkєió $\omega$ ) hace referencia simultáneamente a dos ideas: (i) apropiarse de algo y (ii) tener una disposición afectiva hacia eso de lo que uno se apropia ${ }^{11}$. Este término denota un proceso de familiarización en el que un objeto o una actividad se establece como beneficiosa y propia de la naturaleza (oikeĩov)

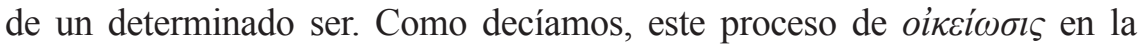
constitución de los seres, que llamaremos familiarización, es una estrategia central en el plan providente de Dios para alcanzar el fin propio de cada criatura y, en últimas, el del todo. Así se puede ver en el siguiente pasaje de Diógenes Laercio.

[Los estoicos] dicen que el animal mantiene como impulso primero el

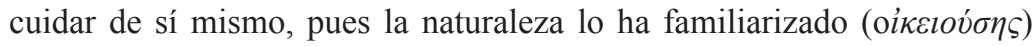
desde el inicio, como dice Crisipo en el libro primero de Sobre los fines, señalando que la primera cosa familiar (oikeĩov) para todo animal es su propia constitución y el conocimiento de la misma. Pues no era conveniente que [la naturaleza] hiciera al animal hostil a sí mismo, tampoco que habiéndolo engendrado ni lo hiciera hostil ni familiar consigo mismo. Por lo tanto, resta decir que al constituirlo lo hizo familiar consigo mismo, pues de este modo repele las cosas dañinas y acerca a sí las familiares $(\text { oik } \varepsilon \tilde{i} \alpha)^{12}$. (DL 7.85 (L\&S 57A y SVF 3.178)).

\footnotetext{
${ }^{9}$ El fin de la vida humana es descrito por Zenón como 'vivir en conformidad con la naturaleza', que es equivalente a vivir virtuosamente, pues él consideraba que somos guiados naturalmente hacia la virtud. Esta misma relación entre el fin y la vida virtuosa fue conservada por los siguientes escolarcas de la Stoa (DL 7.87).

${ }^{10}$ Cicerón en De Fin. 3.62-68 (L\&S 57F) atribuye esta idea a Crisipo. También es defendida por Marco Aurelio en 5.16 (L\&S 63K).

${ }^{11} \mathrm{Al}$ respecto véase la entrada léxica de este término en LSJ y el comentario de Long y Sedley (1987, p. 351). Para un estudio detallado del término oỉkeĩos ver Inwood y Donini (1999, p. 677), especialmente las referencias en la nota 8.

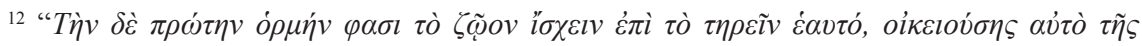

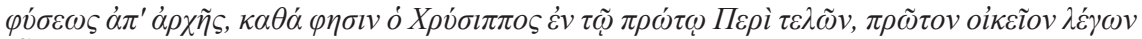

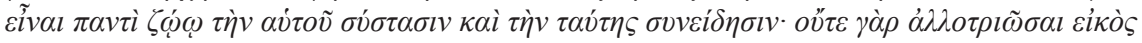


Siendo la naturaleza del mundo gobernada por una mente providente, esta no genera a sus creaturas dejándolas desprovistas de las herramientas necesarias para su supervivencia. Por el contrario, ella no solo las dota de una constitución física conveniente para la satisfacción de sus necesidades y la consecución de sus fines, sino que además hace que en ellas se dé un proceso de familiarización con su propia constitución y que puedan discernir entre las cosas beneficiosas y las dañinas, de tal manera que se dirijan a las primeras y se alejen de las segundas. Así, por ejemplo, la naturaleza dota de cuernos a algunos animales y los hace consientes de que ellos sirven para la lucha (Séneca, Ep. 121.6-15 (1\&s 57b) y Hierocles, 1.34-2.9 (1\&s 57c)). Ahora bien, aunque este proceso de familiarización es una estrategia que la mente providente emplea con todos los seres de la naturaleza, esta maniobra varía y se perfecciona en conformidad con la posición que cada ser ocupa en la jerarquía de la naturaleza.

La naturaleza, dicen [los estoicos], no estableció diferencia entre las plantas y los animales, cuando sin impulso y sensación dirigió a aquellas y surgieron en nosotros algunas cosas de carácter vegetativo. Pero habiéndosele añadido el impulso a los animales por superioridad, haciendo uso de él se dirigen hacia las cosas familiares. Para ellos lo conforme a la naturaleza es el regirse de acuerdo con el impulso. Pero habiendo sido concedida la razón a los racionales para una administración más perfecta, el vivir rectamente $(\delta \rho \theta \tilde{\omega} \varsigma)$ de acuerdo con la razón llega a ser para ellos lo conforme a la naturaleza, pues esta [la razón] se convierte en artesana del impulso ${ }^{13}$. (DL 7.86 (L\&S 57A y SVF 3.178))

La naturaleza, entonces, confiere progresivamente a lo largo de la Scala Naturae diferentes características que permiten llevar a cabo una administración cada vez más perfecta de las entidades. Así, mientras que las plantas efectivamente están físicamente constituidas de manera que reciben

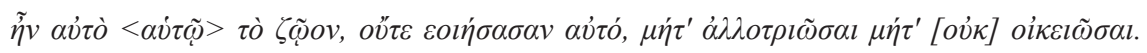

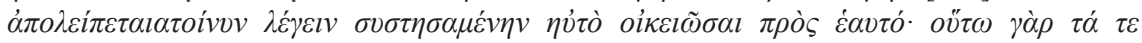

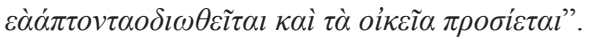

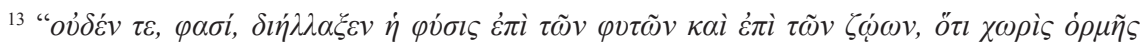

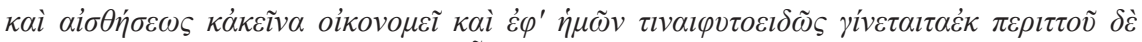

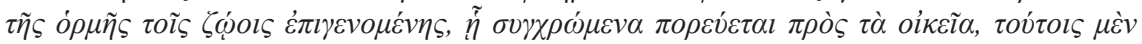

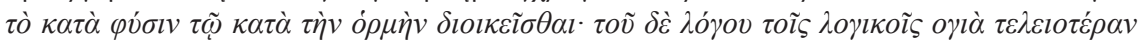

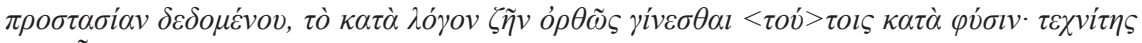

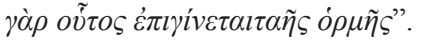


las cosas que son apropiadas a su naturaleza (ej. nutrientes, luz, agua), los animales son dotados de impulsos que les permiten dirigirse en búsqueda de las cosas que reconocen como apropiadas y huir de las dañinas, siendo de esta manera más aptos para la supervivencia. Ahora bien, hemos señalado que de acuerdo a la cosmovisión estoica tanto plantas como animales existen como medios para el beneficio del hombre, por ello a la naturaleza le basta con garantizar su supervivencia, su variedad y su belleza, de modo que constituirlos de esta manera es suficiente para la consecución del fin. Para el hombre, en cambio, hay un fin más elevando: vivir virtuosamente, contemplar e imitar la naturaleza y ser junto con los otros seres racionales ciudadanos del mundo. Este fin supremo solo se alcanza a través de la posesión de la razón y por eso vivir en conformidad con los dictados de la razón -nueva artífice de los impulsos- llega a ser lo propio a la naturaleza humana.

Los estoicos consideran que la racionalidad no es algo con lo que la naturaleza nos haya dotado desde el inicio, pues esta se adquiere gradualmente a lo largo de los primeros siete años de la vida humana a través de la formación de concepciones (Aecio, 4.11. 1-4 (L\&S 39e, SVF 2.83)). Por eso en un principio nuestro comportamiento en nada difiere del de los demás animales. Al igual que ellos, somos movidos por nuestro impulso primero a buscar aquellas cosas apropiadas a nuestra naturaleza (ej. alimento, refugio, salud, abrigo). No obstante, reporta Cicerón, los estoicos consideran que todos estos requerimientos de la naturaleza son solo medios para un fin mayor que el hombre es capaz de descubrir en su adultez. Cuando el hombre adquiere la razón consigue al mismo tiempo la capacidad de contemplar la naturaleza y aprehender la armonía y regularidad de la conducta de las cosas, y llega a valorar esto muchísimo más que aquello hacia lo cual estaba dirigido por naturaleza en un comienzo. En este momento la razón del hombre llega a la conclusión de que la armonía que contempla en el universo constituye el bien humano más alto y por ello la considera digna de imitar. De aquí la formulación del fin humano como contemplar e imitar la naturaleza. La persona considera que de hecho esta armonía es lo único que puede ser realmente considerado como bueno, pues todas las otras cosas que ha perseguido hasta el momento son solo medios para la supervivencia, mientras que aquella no es un medio para algo ulterior sino más bien el fin al que se deben dirigir todas sus acciones. Las otras cosas son preferibles, pero lo único bueno es aquello que no es un medio, sino que es el fin de todo lo demás (Cicerón, De fin. 3. 20-21(L\&S 59D)). 
Cicerón sostiene cómo este bien supremo, la imitación de la armonía del mundo a través de la armonía de nuestras acciones, a pesar de ser aprehendido por el hombre en un momento ulterior de su desarrollo, puede ser concebido como el fin último al que están dirigidas todas esas cosas que la naturaleza desde un inicio nos movió a buscar.

[...] puesto que éste [el sumo bien] está situado en lo que los estoicos llaman ó $о д о \gamma i ́ \alpha v$ (si te parece, nosotros lo llamaremos armonía), puesto que en ello está, entonces, aquello en lo que consiste el bien al cual todas las cosas deben referirse, las acciones virtuosas y la virtud misma, que es la única cosa considerada entre los bienes, aunque se produce después, esta es la única cosa deseable por su naturaleza intrínseca y valor, mientras que ninguno de los que son los primeros objetos de la naturaleza es deseable por causa de sí. Pero dado que aquellas cosas que he llamado funciones propias avanzan desde los inicios de la naturaleza, es necesario que ellas sean dirigidas a esta, de modo que pueda ser dicho correctamente que el fin de las funciones propias es obtener los requerimientos de la naturaleza, pero no que este es el bien último, puesto que la acción virtuosa no está presente en las primeras inclinaciones de la naturaleza; esta es un resultado de ellas y surge posteriormente, como he dicho. Sin embargo, ella es en conformidad con la naturaleza, y esta nos estimula a desearla mucho más fuertemente de lo que somos estimulados por todas las inclinaciones anteriores $^{14}$. (Cicerón, De Fin. 3.21-22 (L\&S 59D))

Vemos, entonces, que no porque la vida en armonía (llamada virtud) sea aprehendida como fin último mediante un procedimiento de la razón, ni porque este sea descubierto con posterioridad en la vida humana, se puede decir que este no es un fin natural en el hombre. Por el contrario, es la naturaleza misma la que nos hace desear la vida en armonía como fin supremo y nos hace sentirnos familiarizados con dicho fin de manera mucho más fuerte de lo que nos hacía sentir respecto de los fines a los que nos

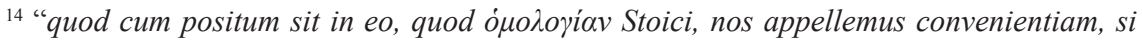
placet,-—cum igitur in eo sit id bonum, quo omnia referenda sint, honeste facta ipsumque honestum, quod solum in bonis ducitur, quamquam post oritur, tamen id solum vi sua et dignitate expetendum est; eorum autem, quae sunt prima naturae, propter se nihil est expetendum. Cum vero illa, quae officia esse dixi, proficiscantur ab initiis naturae, necesse est ea ad haec referri, ut recte dici possit omnia officia eo referri, ut adipiscamur principia naturae, nec tamen ut hoc sit bonorum ultimum, propterea quod non inest in primis naturae conciliationibus honesta actio; consequens enim est et post oritur, ut dixi. Est tamen ea secundum naturam multoque nos ad se expetendam magis hortatur quam superiora omnia".
} 
movía con el impulso primero. Es la naturaleza misma la que nos permite comprender que esto es lo único que puede ser tomado como fin, mientras que todas las demás cosas a las que nos ha inclinado han sido solo medios para llegar a él; ella nos permite aprehender que nuestra naturaleza no llega a su fin a menos que alcancemos a imitar en nuestra vida la armonía del

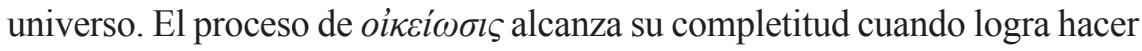
que el humano aprehenda, desee y ejecute el fin último de su vida: la armonía total de sus acciones.

Ahora bien, los estoicos sabían que la mera adquisición de la razón no era suficiente para que los hombres aprehendieran y desearan esta armonía de la vida. Muy por el contrario, podían notar que la mayoría de los humanos adultos vivimos en una constante fluctuación y conflicto entre las acciones que emprendemos. Así lo presenta con claridad Cleantes en el Himno a Zeus en donde señala que los humanos vivimos moviéndonos en todas direcciones en ocasiones en busca del dinero y las riquezas; en otros momentos en busca del honor y la fama; después moviéndonos hacia los placeres y los goces del cuerpo. De este modo, andamos como sin rumbo de un lado hacia otro queriendo llevar una vida buena, pero procurándonos con nuestro desorden nuestro propio mal (Estobeo, 1.1.12 (L\&S 54I, SVF 1.537 v.v. 26-31)). Por ello, concebir la armonía de la naturaleza y ser capaz de imitarla a través de nuestras acciones no es una obra de la mera razón, sino de aquello que

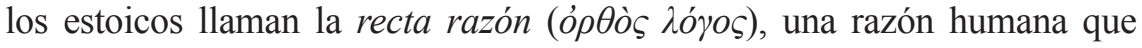
mediante el progreso ha sido llevada a su perfección y que es concebida como semejante a la razón divina.

Gracias a que la recta razón nos permite aprehender la armonía del mundo y reconocer cómo nosotros mismos podríamos llevar a cabo esta armonía en nuestra vida, los estoicos consideran que la recta razón es equivalente a la virtud en el alma, pues la virtud, dicen, es aquel estado de la mente que tiende a hacer la totalidad de la vida armoniosa (DL 7.89 (L\&S 61a, SVF 3.39) y Séneca, Ep. 76.9-10 (L\&S 63 D, SVF 3.200a)). La recta razón se convierte, de esta manera, en un estándar con base en el cual podemos conducir con armonía nuestra vida (DL 7.54 (L\&S 40A, SVF 2.105)). De manera que la acción virtuosa será aquella que se realice en conformidad con los dictados de la recta razón y la acción viciosa aquella contraria a la recta razón (Estobeo, 2.96,18-97.5 (L\&S 59 M, SVF 3.501) y 2.93, 14-18 (L\&S59K, SVF 3.500)). De la mano de esto, aquel individuo que se conduzca en conformidad con la recta razón, llamado por los estoicos el 
hombre sabio, actuará siempre virtuosamente y en consecuencia alcanzará la perfecta armonía de la vida (Estobeo, 2.66,14-67.4 (L\&S 61 G, SVF 3.560)). De aquí que las formulaciones del fin humano como vivir en armonía y vivir virtuosamente sean equivalentes.

La tercera formulación del fin del hombre que hemos mencionado, a saber, establecer una comunidad de seres racionales, aunque está correlacionada con las dos anteriores, contiene un elemento adicional: la referencia a la relación que se espera que el hombre tenga con quienes comparten con él la racionalidad. Dejaremos en suspenso un análisis detallado de esta formulación del fin del hombre, pues su comprensión presupone el entendimiento del concepto de ley natural, cosa que abordaremos en el tercer apartado. Por ahora solo mencionaremos que la mente divina, en su plan providente dirigido a la consecución de este fin, provee a los humanos

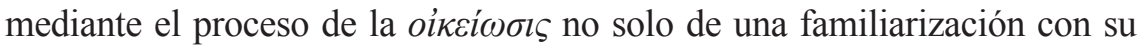
propia constitución, sino también de una familiarización, primero, con su descendencia (lo que explica el cuidado que tienen los padres con sus hijos) y, de una manera progresiva correspondiente al perfeccionamiento del hombre; segundo, con la humanidad entera y todo ser racional. Es esta familiarización la que permite la constitución de la cosmopolis de dioses y humanos que es mencionada en esta tercera formulación de la finalidad humana (Galeno, Nat. Fac. 1.12 (SVF 2.1138); Cicerón, Leg. 1.16.43 (SVF 3. 321) y Cicerón, Rep. 3.39). ${ }^{15}$

Hemos señalado a lo largo de este apartado que el término providencia remite a la finalidad deseada y perseguida por Dios a través de un plan que lleva a cabo en la administración del mundo. Para terminar esta sección es importante señalar el alcance de la providencia, en otras palabras, examinar si todo lo que sucede en el mundo ocurre en conformidad con este plan providente de Dios.

De acuerdo con los estoicos, el plan providente de Dios marca la administración del mundo desde el principio hasta el final de cada ciclo

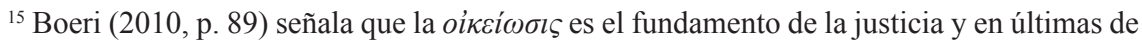
esta cosmopolis porque gracias a ella "el ser vivo racional es capaz de reconocer en los otros la misma razón que aparece como un rasgo propio de sí mismo, lo que lo hace desarrollar un vínculo hacia los otros como sus congéneres".
} 
cósmico. Esta presencia eterna de la providencia es indicada por los estoicos enfatizando que tras la conflagración que marca el final de un ciclo y el inicio de uno nuevo Zeus se repliega en la providencia (Plutarco, comm. not. 1077c-e (L\&S 28 O)), de modo que, en palabras de Long y Sedley (1987, p. 277), "lo que lleva al presente orden del mundo a un fin es ese estado del universo que en su total bondad y sabiduría asegurará la reconstitución del orden del mundo de la mejor manera posible". De la misma manera, señalan, al finalizar el ciclo cósmico Dios purga toda la maldad del mundo a través de esta gran conflagración (Plutarco, comm. not. 1067a (L\&S 46N y SVF 2.606)). Así, conformación y destrucción del mundo se dan como parte de este plan providente de Dios. No obstante, hay que señalar que la presencia de estos mismos males, que obligan a generar la conflagración del mundo y a recrearlo de nuevo, fue al interior del estoicismo un punto de disputa en torno al alcance de la providencia divina. Si bien la administración del mundo se da de principio a fin de acuerdo con la providencia, no es claro que las cosas malas, particularmente las acciones viciosas, sean parte del plan providente de Dios.

Escribe Cleantes en su Himno a Zeus que el universo entero es gobernado voluntariamente por Dios y sigue el camino que él ha trazado (v. 7-8), de modo que ni la cosa más pequeña sucede en el mar, el aire o sobre la tierra separadamente de él ( $\left.\sigma o \tilde{v} \delta i^{\prime} \chi \alpha\right)$, excepto lo que los malos hacen a causa

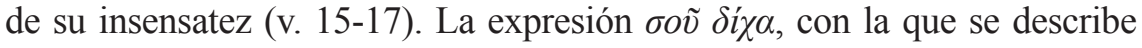
la relación de las acciones malas de los hombres y Dios, remite al hecho de que estas acciones suceden sin la anuencia de Dios o en contra de su voluntad $^{16}$. Esto permite sostener que Cleantes consideraba que las acciones de los hombres malos no suceden en conformidad con la providencia divina. Este alcance limitado de la providencia en el pensamiento de Cleantes es

\footnotetext{
${ }^{16}$ Ver la acepción de $\delta i \chi \alpha$ en el diccionario VOX y la entrada II.3 del LSJ. Allí se muestra como ejemplo la expresión $\pi \dot{\lambda} \lambda \varepsilon \omega \varsigma$ $\delta i \chi \alpha$, que significa "sin anuencia de la ciudad" o "contra la voluntad de la ciudad". Además, confróntese el tratamiento de Inwood (1985, p. 71) y Thom (2006, pp. 96-97) sobre esta expresión, donde critican a quienes la han entendido como refiriéndose a la libertad. Los malos, dicen, no obran más libremente que los buenos.

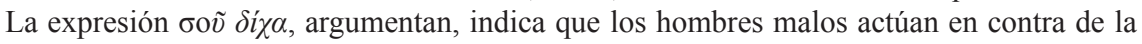
recta razón que, justamente, como veremos, comanda a los seres comportarse de tal manera que puedan alcanzar el fin deseado por la providencia. Meijer $(2007$, p. 218) dice que esta expresión admite la posibilidad de que las acciones de los malos no sean directamente deseadas por Dios, aunque se sostenga que ellas suceden en conformidad con su gobierno. En el siguiente apartado trataremos de explicar cómo los estoicos lidiaron con esta tensión.
} 
reportado también por Calcidio, quien señala que, considerando aquel que la providencia es equivalente a la voluntad de Dios, sostenía que no todo en el mundo sucede de acuerdo con aquélla (Calcidio 144 (L\&S 54U, SVF $2.933))^{17}$.

Plutarco critica agudamente esta postura, mostrando lo absurdo de suponer que las acciones de los malos suceden en contra de la voluntad del dios artífice del mundo. De la mano de esto nos deja saber que Crisipo cambió esta postura por una que a su parecer era aún más absurda. Él escribe:

Pues, así, ninguno de los seres que tienen alma ha sido tan mal organizado que en contra de su voluntad su pie se mueva hacia delante o su lengua emita un sonido o su cornamenta hiera o sus dientes muerdan, pero es necesario que la mayoría de estas cosas sucedan a dios, si en contra de su voluntad los malos, siendo partes de él, engañan, viven despreocupadamente, saquean y se matan unos a otros. Si, sin embargo, como dice Crisipo, ni siquiera la más pequeña de sus partes es de otra manera sino, ciertamente, en conformidad con la voluntad de Dios y, además, todo ser animado por naturaleza se detiene o se mueve del modo como aquél lo conduce, gira, detiene y dispone, "esto tiene un sonido más depravado que aquello"18. (Plutarco, comm. not. 1076d-e (SVF 2. 1168))

Las acciones de los malos son, entonces, el punto de inflexión en la concepción estoica de la providencia. Para Cleantes, estas acciones demostraban que algunos movimientos de la naturaleza suceden en contra de la voluntad divina. Esto, como dice Plutarco, produce una visión del mundo como un ser mal organizado cuyas partes no obedecen a la voluntad del todo. No obstante, Cleantes insiste en su Himno a Zeus que Dios sabe cómo lidiar con la existencia de estos males que son contrarios a su voluntad.

Sin embargo, tú sabes poner en su límite lo que está desproporcionado, ordenar lo desordenado y las cosas no amadas son amadas por ti,

\footnotetext{
${ }^{17}$ Véase el comentario a este pasaje de Long y Sedley, 1987, p. 333.

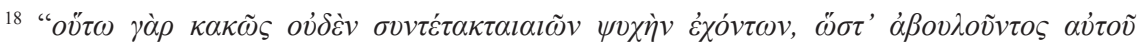

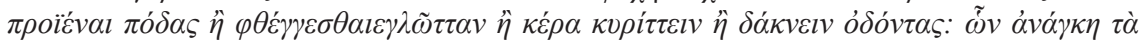

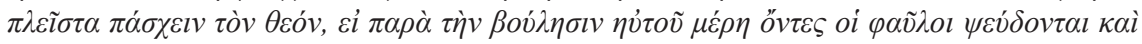

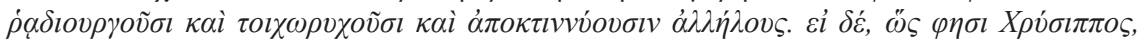

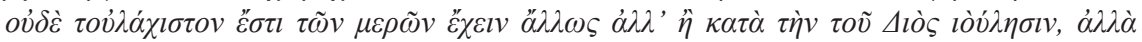

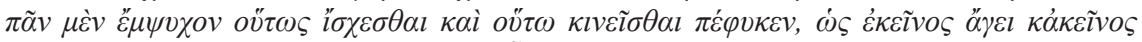

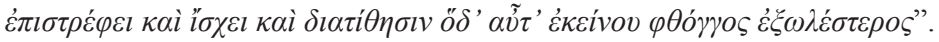


pues así has unido en una todas las cosas buenas con las malas, de modo que llega a haber una razón de todas las cosas existiendo siempre ${ }^{19}$. (Estobeo, 1.1.12 (L\&S 54I, SVF 1.537 v. 18-21))

Hay en estos versos una referencia a la eterna razón común como resolución de Cleantes al problema del conflicto entre el mal del mundo y la providencia divina. Cleantes asegura que si bien estos males no son conformes a la voluntad providente de Dios, él tiene la capacidad de darles su lugar en el mundo creando una unidad de las cosas buenas y las malas, una eterna razón común que armoniza todas las cosas.

Crisipo, en contraste, considera que las acciones viciosas son también partes del plan providente de Dios, suceden en conformidad con su voluntad. Curiosamente, para defender cómo un dios bueno puede querer la existencia de cosas malas, Crisipo recurre también a la existencia de esta eterna razón común conforme a la cual está constituido el mundo. Dirijámonos, entonces, al análisis de esta para comprender a cabalidad la concepción estoica de la constitución del mundo y, particularmente, su explicación de la existencia del mal en un cosmos creado por el artificio divino.

\section{La ineludible racionalidad del mundo}

Aulo Gelio sostiene QUe en el LiBro IV de Acerca de la providencia Crisipo enfrentaba a aquellos que sostenían que si el mundo estuviera gobernado por la providencia no debería existir ninguno de los males que en él percibimos. De acuerdo con ellos, la tesis según la cual el plan providente de Dios está dirigido al beneficio del hombre y a la consecución de su virtud, parece refutada, por un lado, por las innumerables tribulaciones y enfermedades

que padecen los hombres y, por el otro, por el estado vicioso prácticamente universal de los seres humanos ${ }^{20}$. Gelio cita dos estrategias argumentativas que Crisipo desarrolló para enfrentar esta crítica.

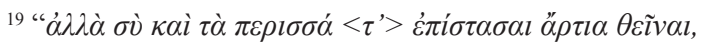

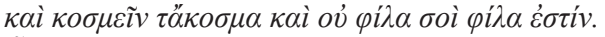

$\tilde{\omega} \delta \varepsilon \gamma \grave{\alpha} \rho \varepsilon \dot{\varepsilon} \varsigma \tilde{\varepsilon} v \pi \alpha \dot{\alpha} \tau \tau \alpha \sigma v v \dot{\rho} \rho \mu о \kappa \alpha \varsigma \varepsilon \dot{\varepsilon} \sigma \theta \lambda \dot{\alpha} \kappa \alpha \kappa o \tilde{l} \sigma l v$,

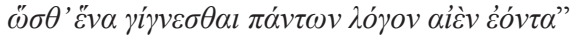

${ }^{20}$ La primera razón se encuentra esgrimida en Gelio, Noc. At. 7.1.1 (L\&S 54Q, SVF 2.1169).

La segunda se encuentra en Plutarco, comm. not. 1076d-e (SVF 2. 1168).
} 
La primera estrategia, como señala el mismo Crisipo, es de origen Platónico y se desarrolla de la siguiente manera:

Nada en absoluto - dice- es más temerario que los que opinan que podrían existir los bienes si no existieran al mismo tiempo los males. Pues, siendo los bienes contrarios a los males, es necesario que ambos existan, opuestos entre sí y cada uno de ellos conservados, por así decirlo, por el mutuo esfuerzo opuesto; o, mejor, ninguna cosa contraria existe sin otra contraria $^{21}$. (Gelio, Noc. At. 7.1.2-3 (L\&S 54Q, SVF 2.1169))

De acuerdo con Crisipo, la existencia de un opuesto implica de suyo la existencia del otro: bien y mal, justicia e injusticia, valentía y cobardía, verdad y falsedad, son todas ellas interdependientes. Este mismo argumento crisipiano es reportado por Plutarco, quien menciona que el vicio ocurre en conformidad con la razón ( $\lambda o ́ \gamma o \varsigma$ ) de la naturaleza, pues la existencia del bien presupone la existencia del mal (Plutarco, Stoic. rep. 1050f (L\&S 61R, SVF 2.1176)). Vemos en este argumento nuevamente una apelación a esa unidad de los contrarios que es constitutiva de la eterna razón universal que era mencionada por Cleantes. En este argumento esgrimido por Crisipo se puede ver que esta racionalidad en conformidad con la cual está constituido el mundo exige a su divino artífice la creación de tanto bienes como males. En el Himno a Zeus esta unidad de los bienes y los males no se presentaba como una exigencia de la racionalidad sobre Dios, sino como un logro de Dios dada la existencia de los males. En ambos autores, sin embargo, la racionalidad del mundo conlleva la coexistencia de estos opuestos.

La segunda estrategia argumentativa desarrollada por Crisipo señala que si bien la naturaleza o la providencia ha creado la estructura del mundo y del hombre, no ha sido el propósito principal de la naturaleza (principale naturae consilium) la creación de las enfermedades, debilidades y demás indisposiciones que padece la humanidad. Ello, afirma Crisipo, no sería compatible con la providencia que es autora y progenitora de las cosas buenas.

Pero, dice, cuando generaba muchas y magnas cosas y engendraba cosas adecuadísimas y utilísimas, nacieron al mismo tiempo también otras cosas

\footnotetext{
21 "Nihil est prorsus istis," inquit, "insubidius, qui opinantur bona esse potuisse, si non essent ibidem mala. Nam cum bona malis contraria sint, utraque necessum est opposita inter sese et quasi mutuo adversoque fulta nisu consistere; nullum adeo contrarium est sine contrario altero".
} 
desfavorables, que eran coherentes con esas mismas cosas que producía ${ }^{22}$. (Gelio, Noc. At. 7.1.9 (L\&S 54Q, SVF 2.1170))

Las cosas desfavorables a los humanos no son, entonces, parte del propósito principal de la providencia divina, sino secuelas necesarias

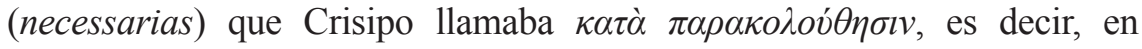
conformidad con el sobrevenir. Como ejemplo de esto Crisipo señala que, siendo el propósito principal de la naturaleza constituir a los humanos como seres racionales, este mismo propósito demandó (postulavit) que los huesos del cráneo fueran muy delgados. A esta útil constitución del cráneo humano se siguió que estuviera más propenso a la muerte (Gelio, Noc. At. 7.1.12 (L\&S 54Q, SVF 2.1170)) ${ }^{23}$. A diferencia de Cleantes, Crisipo no afirmó que estos males fueran contrarios a la voluntad divina, sino que sostuvo que ellos son secuelas no deseadas en sí mismas por la divinidad, y solo en la medida en que son consecuencias de sus propósitos principales. Ahora bien, recalcaremos que estas cosas que se dan en conformidad con el devenir son presentadas por Crisipo como necesarias, como demandas impuestas a Dios en la ejecución de su plan providente. Dios no podía elegir que, siendo el cráneo humano apto para la inteligencia y por ello delgado, este no fuera frágil y en consecuencia desfavorable para la conservación de la vida. Hay una racionalidad que Dios no puede quebrantar cuando crea el mundo. Esta racionalidad, sin embargo, es una característica más de la mente divina que es artífice del cosmos.

\footnotetext{
22 "Sed cum multa," inquit, "atque magna gigneret pareretque aptissima et utilissima, alia quoque simul adgnata sunt incommoda his ipsis quae faciebat cohaerentia".

${ }^{23}$ Salles muestra que esta segunda estrategia también es de origen platónico, indicando que el ejemplo del cráneo se encuentra ya en Timeo 75a4-c7. Él señala además que es plausible pensar que Cleantes fue el primer estoico en usar la noción de consecuencias concomitantes en el contexto de su explicación de cómo la conflagración del mundo es compatible con la bondad divina (Salles, 2005, pp. 67-73). Ahora bien, aunque este modelo de las causas concomitantes puede ayudarnos a entender cómo la destrucción del mundo es compatible con la buena voluntad divina, parece que Cleantes no hizo uso de este modelo para conciliar la existencia de todos los males del mundo con la bondad divina, a la manera como lo hizo Crisipo. De ser así, la existencia de éstos no lo habría llevado a limitar el alcance de la providencia divina.

Por otro lado, Salles nos advierte agudamente que el ejemplo del cráneo no se corresponde con la concepción crisipiana de la mente según la cual la inteligencia tiene su centro en el corazón y no en la cabeza (Salles, 2005, p. 75). Ahora bien, aunque el ejemplo y la teoría tengan su origen en Platón, no hay razón para dudar del testimonio de Gelio, según el cual la teoría de los efectos concomitantes fue adoptada por Crisipo para conciliar la existencia de los males y la bondad divina.
} 
De esta manera, la segunda estrategia argumentativa de Crisipo deja ver que hay dos funciones de la divinidad que están correlacionadas en la constitución del mundo. Por un lado, está la voluntad de Dios, cuyo plan principal (principale consilium) se dirige al bien del hombre. Por otro lado, está la racionalidad divina, que impone una lógica que es imposible de quebrantar al momento de la implementación de este plan. Ya en su primera estrategia argumentativa se veía que dicha racionalidad establecía exigencias de carácter lógico: un opuesto no se puede dar si no se da también su opuesto. De modo que, siendo el deseo de Dios constituir los bienes, su racionalidad establece que estos no pueden existir si no se dan también los males. En la segunda estrategia, se ve que la racionalidad de Dios establece también que se deben dar unas condiciones causales necesarias para la consecución de los fines deseados ${ }^{24}$.

La distinción entre estas dos funciones de Dios -la racionalidad y la voluntad-permite a Crisipo enfatizar que esta racionalidad no está sometida a la voluntad de Dios, que no es algo que él pueda cambiar voluntariamente o decidir no obedecer en la configuración del mundo. Por el contrario, la racionalidad de Dios se impone como una función independiente y coexistente con la voluntad divina. Así, la racionalidad no establece cuál fin debe escoger la voluntad divina, ni la voluntad divina establece bajo qué lógica debe la racionalidad constituir la realidad. Más bien, el Dios artífice debe operar en la constitución del mundo coordinando simultáneamente estas dos funciones suyas. Esto permite a los estoicos comprender a la naturaleza como un organismo activo que conjuga estas dos funciones de su artífice. Así lo muestra el siguiente reporte de Diógenes Laercio ${ }^{25}$ :

\footnotetext{
${ }^{24} \mathrm{Al}$ respecto véase: Bénatoïl, 2009, p. 38.

25 Ver también el testimonio de Diógenes Laercio donde reporta que los estoicos sostenían que el mundo es ordenado en conformidad con el intelecto y la providencia

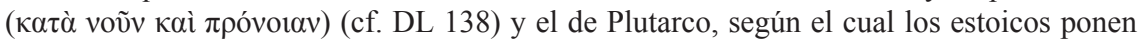

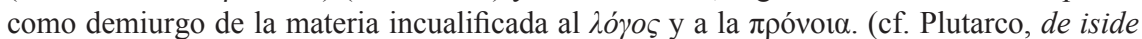
et osiride 369a, SVF 2. 1108). En adición a esto, ver los argumentos de Zenón y Crisipo mediante los cuales pretenden probar que el cosmos es un ser, no meramente inteligible, sino también inteligente, es decir, un ser que hace uso de la razón (DL 7.142-143, Sexto Empírico, Adv. Math. 9. 98 y 101-104, Cicerón, Nat. Deo 2.20-22; analizados en Salles, 2013), de la mano del pasaje de Cicerón que explica la providencia en términos de los movimientos voluntarios del mundo, que incluyen deseos, propósitos e impulsos (Cicerón, Nat. Deo. 2.58).
} 
(i) La naturaleza es una fuerza que se mueve a partir de sí misma, que produce y preserva en su ser a su descendencia en conformidad con unas

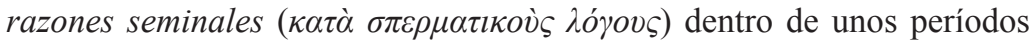
definidos, y continúa realizando las acciones a partir de las cuales ellos surgen. (ii) Además, ella está dirigida a la utilidad y al placer, como es evidente a partir de la creación del hombre ${ }^{26}$. (DL 7.148 (L\&S 43E, SVF 2.1022))

Dos rasgos son atribuidos aquí a la naturaleza: (i) actúa en conformidad con unas razones seminales y (ii) está dirigida al placer y la utilidad. El segundo es una referencia clara a la providencia en conformidad con la cual está administrado el mundo, que es una función de la voluntad divina. El

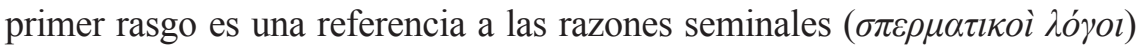
en conformidad con las cuales este está constituido, que es una función de la racionalidad divina. Así lo sostiene Aecio, quien dice que, de acuerdo con los estoicos, Dios es un ser inteligente que ordenadamente procede a la creación del mundo y que comprende todas las razones seminales de acuerdo con las cuales todas las cosas surgen (Aecio, 1.7.33 (SVF 2.1027, L\&S 46A). Así lo menciona también Diógenes Laercio quien afirma que Dios era llamado por los estoicos la razón seminal ( $\sigma \pi \varepsilon \rho \mu \alpha \tau \imath \kappa o ̀ \varsigma \lambda o ́ \gamma o \varsigma)$ del mundo (DL 7.136 (L\&S 46b, SVF 1.102)).

Esta referencia a la razón divina con la metáfora de una semilla racional fue fuertemente explotada por los estoicos para explicar su función en la constitución del mundo. Del mismo modo, dicen que la semilla de un árbol determina en qué momento cada una de sus partes se generará (primero el tallo, luego las ramas y la flor, y finalmente el fruto), en la razón seminal del mundo está contenido en qué momento debe surgir cada una de sus partes (ej. plantas, animales y personas) (Ario Didimo, Fr. 38 en Estobeo, eclog. 1.153.7-22 (S.V.F. 1.497.)) y también en qué momento debe perecer (Calcidio 293 (L\&S 44 E)). De allí que en los reportes de Aecio y de Diógenes que acabamos de traer se hable de esta razón seminal como encargada del ordenamiento del mundo, ordenamiento que no solo fija los períodos en que cada cosa debe acaecer, sino que establece además las exigencias lógicas y causales mencionadas anteriormente.

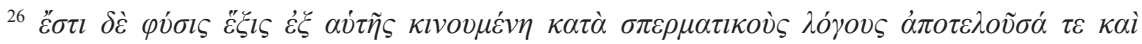

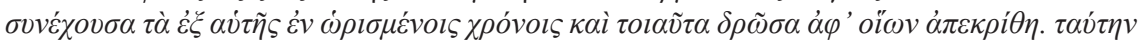

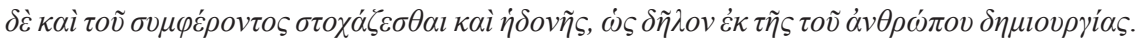


Ahora bien, la razón universal fue también llamada por los estoicos destino $^{27}$. Bénatouil considera que mediante este nombre los estoicos, si bien remiten a la misma realidad cósmica que es referida mediante la metáfora de la semilla del mundo (ej. el $\lambda o ́$ os divino), aluden a un contexto cósmico diferente. Él afirma (2002, p. 306): "En tanto que Destino, Dios ya no es descrito mediante una metáfora embriológica, sino como lo que ordena lógica y temporalmente cada parte del mundo y le prescribe un cierto destino coordinado con cada una de las otras partes". Si embargo, esta no nos parece una razón válida para establecer una distinción entre las dos nociones, porque a la razón seminal se le adjudica también como función determinar el orden temporal en el que cada una de las partes del mundo debe ocurrir. Posteriormente, Bénatouil (2002, p. 306) señala: "El $\lambda o ́ \gamma o \varsigma$ [Destino] es eso «en conformidad con lo que», «según lo cual», «de acuerdo con lo que», todos los acontecimientos llegan a ser más que aquello que los produce directamente. La fórmula importante aquí es $\kappa \alpha \tau \grave{\alpha} \lambda o ́$ jov que se aplica a todas las cosas". Esta, nuevamente, nos parece una razón ilegítima para distinguir el destino y las razones seminales porque los estoicos también

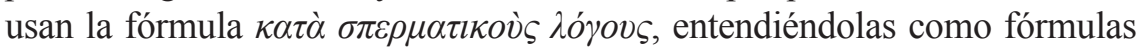
de acuerdo con las cuales la divinidad crea el mundo. En el pasaje de Aecio citado atrás, él decía que los estoicos consideraban que Dios abarca todas las razones seminales en conformidad con las cuales todas las cosas surgen

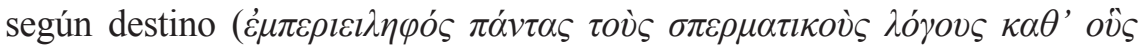

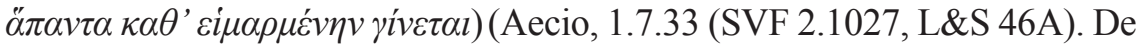
modo que tanto el destino como las razones seminales son descritos como fórmulas en conformidad con las cuales Dios organiza el mundo.

Pese a no estar de acuerdo con las razones que Bénatouil esgrime para distinguir entre estos dos conceptos, consideramos que hay otro motivo para establecer una distinción entre ellos. En efecto, el destino es descrito por los estoicos como una cadena de causas según la cual las cosas pasadas han sucedido, las presentes están sucediendo y las futuras sucederán de modo inexorable ${ }^{28}$. Esta metáfora es producto de la teoría causal de los estoicos, de

\footnotetext{
${ }^{27}$ Ver: Lactancio, De vera sap. 9 (SVF 1. 16); Estobeo, eclog. 1.11.5a (SVF 1.87); DL, 7.135 (L\&S 46b, SVF 1.102); Cicerón, Nat. Deo. 1.39 (L\&S 54B, SVF 1.1077); Estobeo, eclog. 1.79.1 (SVF 2.913); DL, 7.149 (SVF 2.915); Plutarco, Stoic. rep. 1050b (SVF 2.937); Alejandro de Afrodisia, Fat. 192.1.28 (SVF 2.945); Plutarco, Stoic. rep. 1056b (SVF 2.997).

${ }^{28}$ DL, 7.149 (SVF 1. 175, 2.915); Aecio, 1.28.4 (L\&S 55J, 2.917); Nemesio, Nat. Hom. 37 (SVF 2.918); Alejandro de Afrodisia, De anima 185.1 (SVF 2.920); Cicerón, div. 1.55.125
} 
acuerdo con la cual todo efecto es un incorpóreo que se produce cuando dos o más cuerpos, que fungen como causas, entran en relación. Así, por ejemplo, el cuchillo, un cuerpo, es causa para la carne, otro cuerpo, del predicado "ser cortada" 2 . Esto genera un vínculo causal entre los diferentes seres del mundo, expresado con el nombre de cadena de causas, que fue descrito por los estoicos como una relación simpática del mundo consigo mismo en donde lo que pasa a una de sus partes afecta a las otras. Esta relación de causa con causa remite a una conexión sincrónica de todos los cuerpos del mundo que es adjudicada al destino ${ }^{30}$ ([Plutarco], Fat. 11 574e (SVF 2.912)). Pero el destino además produce una conexión diacrónica, puesto que, afirman los estoicos, todo lo que sucede en el mundo está vinculado con algo que lo antecede por ser su efecto $\mathrm{y}$, también, todas las cosas del mundo están vinculadas con un evento posterior por ser su causa (Alejandro de Afrodisia, Fat. 191.30-192.6 (SVF 2.945, L\&S 55n)). Esta ya no es una conexión sincrónica de causa con causa, sino una conexión diacrónica de las causas con sus efectos que da unidad a las cosas desde el inicio hasta el final del ciclo cósmico. Esta unidad se debe, afirma Crisipo, a que no es posible que del mismo grupo de causas se sigan efectos diferentes. Por ello, todo lo que ha sucedido, sucede y sucederá en el mundo es consecuencia inexorable de este conjunto de causas. Así, la cadena de causas llamada destino, tiene la función de dar unidad diacrónica y sincrónica al mundo, mediante el ordenamiento espacial y temporal de los seres, otorgando así de modo necesario a cada entidad un lugar y espacio determinado en el ordenamiento del todo.

Ahora bien, de acuerdo con lo que hemos dilucidado, el $\lambda o ́ \gamma o \varsigma$ divino establece una racionalidad en la naturaleza según la cual el artífice del mundo debe ejecutar su plan. Esta racionalidad comprendida como las

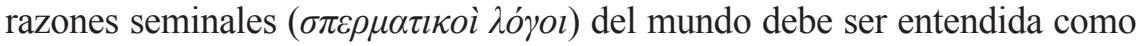
un conjunto de fórmulas inquebrantables que imponen unas condiciones causales y lógicas para la producción de los efectos buscados, un orden que se debe cumplir para la consecución de los mismos. Una vez establecidos los fines, la divinidad debe constituir un plan para la consecución de los mismos acorde con esta racionalidad. No obstante, si los fines fueran diferentes, si la divinidad, por ejemplo, no fuera filántropa sino misántropa, se generaría a

(SVF 2.921). Ver también las definiciones recopiladas en SVF 2.945-951.

${ }^{29}$ Sexto Empírico, Adv. Mat. 9.211 (L\&S 55B, SVF 2.341); Clemente, Strom. 8.9.26.3-4 (L\&S 55c) y Clemente, Strom. 8.9.30. 1-3 (SVF 2.349, L\&S 55D).

${ }^{30}$ Ver sobre este punto el cuidadoso estudio de Susan Meyer (2009). 
partir de su voluntad una cadena de causas completamente diferente, cadena que en todo caso debería respetar las fórmulas generatrices del mundo. Por tal motivo, las meras razones seminales en conformidad con las cuales la divinidad constituye el mundo no son suficientes para determinar la cadena causal que se establecerá y, en consecuencia, no bastarán para determinar inexorablemente lo que ha de suceder a cada cosa del mundo. En cambio, la conjunción de la voluntad divina y su racionalidad sí da como resultado un ordenamiento que determina de modo necesario todo lo que ha de suceder a lo largo del ciclo cósmico. Deseando Dios crear el mejor mundo posible y siendo inquebrantables las fórmulas generatrices del mundo, por necesidad él constituye el mundo de la manera como lo hace. Por ello el destino, si bien es descrito en la mayoría de fragmentos como la racionalidad divina, es explicado en otros como la combinación de la racionalidad divina y la providencia. Así se ve en los siguientes testimonios de Estobeo (1.79.1-12 (L\&S 55M, SVF 2.913)); Eusebio, Preap. ev. VI 263c. (SVF 2.914)).

En el segundo libro de Sobre las estaciones, en el Sobre el destino, y en otros libros esporádicamente [Crisipo] se expresa de muchas maneras diciendo: "el destino es la razón del mundo", "la razón de las cosas organizadas en el mundo por la providencia", "la razón de acuerdo con la cual las cosas que han sucedido sucedieron, las que están sucediendo suceden, y las que sucederán van a suceder" ${ }^{\prime \prime}$.

[...] Crisipo dice que el Hado es un cierto ordenamiento determinado y concluido. Y que el destino es una cierta cadena o bien desde la voluntad de Zeus o bien desde cualquier otra cosa que sea su causa ${ }^{32}$.

De modo que el destino sí puede ser descrito como la racionalidad del mundo, pero no solamente como tal, sino como aquella establecida en conformidad con la providencia. Por ello Eusebio dice que el destino es una cadena de causas que surge a partir de la voluntad de Dios. Estos dos factores reunidos producen el ordenamiento inexorable que es llamado destino (Gelio Noct. At. 7.2.3 (L\&S 55 K, SVF 2.1000)).

Habiendo considerado cuál es la función divina denominada mediante

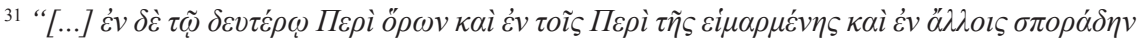

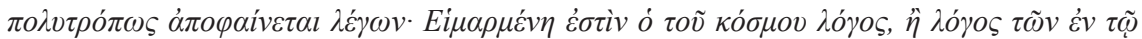

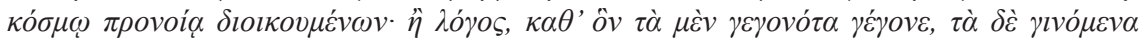

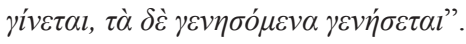

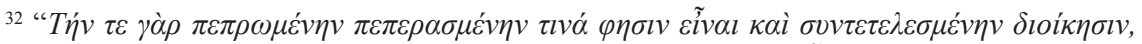

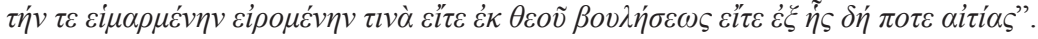


el nombre de $\lambda o ́ \gamma o \varsigma$ y la interrelación que esta tiene con la voluntad divina, terminaremos este apartado señalando también el alcance de esta última, es decir, si todo sucede en conformidad con este $\lambda o ́ \gamma o \varsigma$. La razón divina opera de principio a fin de cada ciclo cósmico. Así, cuando la razón universal avanza a lo largo del tiempo seca todo y lo torna a sí misma produciendo la gran conflagración que marca el final del ciclo cósmico. Allí retorna a lo que los estoicos llaman razón primera ( $\pi \rho \tilde{\omega} \tau o \varsigma \lambda \dot{o} \gamma o \varsigma)$, de acuerdo con la cual

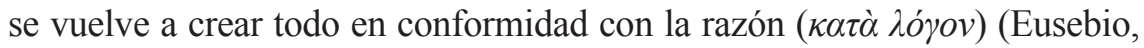
Praep. ev. 15.19.1-2 (L\&S 52D, SVF 2.599)). Pero el alcance de la razón no solo se extiende de principio a fin a lo largo del ciclo, sino que además los estoicos sostienen que todo sucede en de acuerdo con ella. Así lo sostenía Cleantes, según el testimonio del Himno a Zeus que hemos mencionado; también, repetidamente, Crisipo, quien afirmaba que nada sucede sino en conformidad con la razón universal. De acuerdo con él, toda cualidad de la materia y todo movimiento suceden en conformidad con la razón de Dios. Ni siquiera el movimiento más insignificante como el parpadeo de los ojos, ni la cualidad más pequeña como el número de cabellos suceden de otro modo que en concordancia con esta eterna razón universal (Plutarco, Stoic. rep. 1049f (SVF 2.937), 1050A, 1056c.).

\section{Carácter prescriptivo del deber y la ley natural}

Hemos SeÑalado hasta aquí Que la voluntad divina está dirigida a la consecución del bien o fin de cada entidad particular y al fin último de la naturaleza como un todo, pero que, no obstante, su propia racionalidad exige o armoniza la coexistencia de los bienes y los males. En otras palabras, pese a que todo lo que sucede en el mundo hasta el más mínimo detalle es creación divina, por ser este el único principio activo del mundo capaz de dar forma y movimiento a la materia, muchas de las entidades naturales no alcanzarán el fin con miras al cual el artífice del mundo las ha creado. Así, algunas plantas no lograrán producir su fruto, algunos animales no tendrán descendencia, algunos humanos -si no muchos-no vivirán virtuosamente. En lo que sigue sostendremos que es debido a esta tensión en la creación divina que resultó de gran importancia en el estoicismo la introducción de dos nociones: el

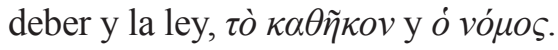

De acuerdo con lo que hemos mencionado, como estrategia para que cada entidad cumpla su fin, la divinidad se vale en la administración del mundo

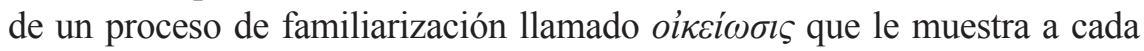
entidad cómo funciona su propia naturaleza y qué cosas le son convenientes y 


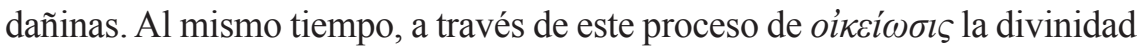
permite a las criaturas discernir el tipo de comportamiento que es apropiado a su naturaleza. Tal comportamiento fue llamado por los estoicos desde Zenón

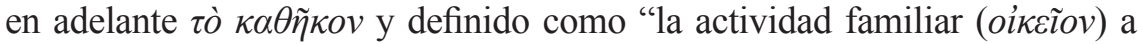

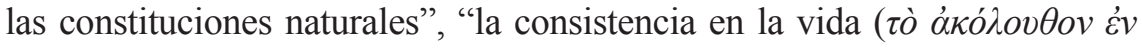

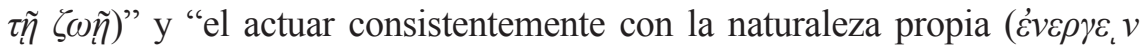

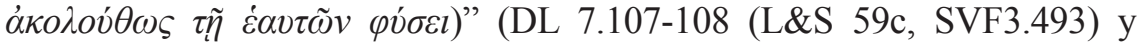
Estobeo, 2.85.13 (L\&S 59B, SVF 3.494)). Esta noción refiere al hecho de que algo encaja o es adecuado a una entidad y a que esto constituye su deber ${ }^{33}$. Así, con ella se señala que en la naturaleza hay un aspecto normativo que indica a los seres cuál es el comportamiento adecuado a su constitución o qué deben realizar.

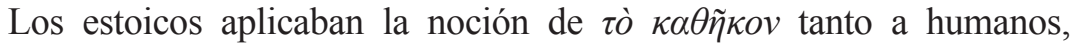
como a plantas y animales, pues afirman que en todos ellos podemos discernir comportamientos que no se ajustan a su naturaleza: un animal que no caza adecuadamente, una planta que no tiene suficientes hojas para proteger sus frutos, un hombre que no procura su salud, son todos casos de comportamientos, llamados por los estoicos, contrarios a lo apropiado ( $\pi \alpha \rho \grave{\alpha}$

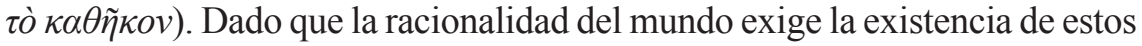
movimientos, es importante establecer para cada entidad un paradigma de comportamiento que le sirva como guía para alcanzar el fin que la voluntad divina le ha demarcado. De este modo, la noción de $\tau \grave{o} \kappa \alpha \theta \tilde{\eta} \kappa o v$ sirve como un término medio para conciliar esta tensión existente entra la voluntad y la racionalidad divina.

Ahora bien, aunque el concepto de $\tau \hat{o} \kappa \alpha \theta \tilde{\eta} \kappa o v$ se extiende a lo largo de la Scala naturae, este cobra especial importancia en el ámbito de lo humano, pues es central en la teoría ética estoica para discernir las acciones conformes al deber, las contrarias al deber y las que no son ni lo uno ni lo otro. Así, los estoicos dicen que el deber es realizar las acciones que son dictaminadas por la razón, tales como cuidar de los padres, hermanos e hijos; pasar tiempo con los amigos; luchar por la patria y cuidar la salud. Lo contrario al deber es realizar las acciones que la razón prohíbe, tales como ser negligente con los padres, no tener simpatía con los amigos, traicionar la patria. Lo que no es ni contrario ni conforme al deber es quello que la razón ni comanda ni prohibe,

\footnotetext{
${ }^{33}$ Véase la entrada II del término $\kappa \alpha \theta \dot{\eta} \kappa \omega$ en LSJ.
} 
acciones tales como sostener una ramita, mover la naríz, etc. (DL 7.108109 (L\&S 59e, SVF3.495,496) y Estobeo, 2.85.13 (L\&S 59B, SVF 3.494)). Tanto necios como sabios, afirman los estoicos, realizan acciones que son conformes al deber: los unos y los otros pueden cuidar a sus padres, devolver un depósito, luchar por la patria. No obstante, solo los hombres que han alcanzado el máximo progreso moral realizan estas acciones virtuosamente. Para expresar esta diferencia, los estoicos hacen una distinción entre los deberes perfectos ( $\tau \dot{\varepsilon} \lambda \varepsilon \imath \alpha \kappa \alpha \theta \dot{\eta} \kappa o v \tau \alpha$-perfecta officia) y los intermedios ( $\mu \dot{\sigma} \sigma \alpha \kappa \alpha \theta \dot{\eta} \kappa o v \tau \alpha-m e d i a$ officia), denotando con ello no dos tipos de acción diferentes, sino dos modos distintos de hacer la misma acción: el modo en que lo haría una persona virtuosa y el modo en el que lo haría una persona que aún no lo es (Estobeo, 2.85.13 (L\&S 59B, SVF 3.494) y Cicerón, fin. 3. 58-59 (L\&S 59f) $)^{34}$. De suerte que el fin último de nuestra naturaleza o el deber perfecto consiste en la realización virtuosa de estas acciones que son conformes a nuestra naturaleza. Esto, como hemos visto, equivale a la perfecta armonía de nuestras acciones, a actuar siempre en conformidad con los dictados de la recta razón.

En este punto podemos establecer el estrecho vínculo que tiene la noción de $\tau \grave{o} \kappa \alpha \theta \tilde{\eta} \kappa o v$ con la de ley natural. De acuerdo con Zenón, la ley natural (naturalis lex) es una fuerza que prescribe realizar las cosas rectas y prohíbe las contrarias (Cicerón, Nat. Deo. I.36. (SVF 1. 162)). Esta fuerza natural es descrita por los estoicos como la mente de dios, más particularmente como la recta razón divina (Cicerón, De leg. II.8 (SVF 3.316); Rep. I.19; Nat. Deo. 2.154). En contraste con la ley humana, que se da solo por convención y válida solo en momentos y lugares específicos, la ley natural es tan eterna, universal e inmutable como lo es la mente de dios. Ahora bien, esta recta razón que reside en la mente divina es equivalente a la recta razón que adquiere el hombre cuando alcanza el más alto punto de su desarrollo moral e intelectual. Por eso, los estoicos dicen que cuando el humano llega a ser sabio, la ley descansa también en su mente (Cicerón, De leg. II.11 (SVF. 3.318); De leg. I. 6,18 (SVF 3. 315); Rep. 3.33) 35. Nuevamente aquí los

\footnotetext{
${ }^{34}$ Ver también la explicación de estos conceptos de Long y Sedley, 1987, p. 365.

${ }^{35}$ Long (1968, p. 334) e Inwood (1985, pp. 107-108) describen esta recta razón como un conjunto de imperativos de la mente divina y la mente humana que sirven como criterio para la acción virtuosa. Boeri en cambio prefiere presentar la recta razón como una disposición racional perfecta de la mente del sabio, más que como un conjunto de prescripciones
} 
estoicos argumentan que, pese a su tardío descubrimiento, podemos afirmar que tenemos conocimiento de esta ley por naturaleza. En el libro segundo de Sobre lo bello, Crisipo argumentaba que así como la virtud de un caballo o un árbol existen naturalmente aunque se presentan cuando estos alcanzan su culmen, así mismo la virtud del hombre, la completa de su razón, también se da por naturaleza. Es la naturaleza la que a través de nuestro pleno desarrollo implanta en nosotros la recta razón que nos permite distinguir lo conforme y lo contrario al deber (DL, VII.128 (SVF 3.308); Cicerón, De leg. I 12.33 (SVF 3.317)). Cicerón resume la noción estoica de ley natural y su vínculo con la noción de deber así: "La ley verdadera es sin duda la recta razón que es acorde con la naturaleza, difundida en todos, inalterable, eterna, que convoca al deber prescribiendo, y que vetando aparta del delito ${ }^{36}$ (Cicerón, Rep. 3.33 (L\&S 67 S, SVF 3.325))".

Ahora bien, es importante tener muy presente aquí que esta ley natural es identificada no con la razón divina, que exige la coexistencia de bienes y males, sino con su recta razón, cuya función es prescribir las acciones rectas y prohibir las contrarias. Esto permite distinguir dos conceptos que los

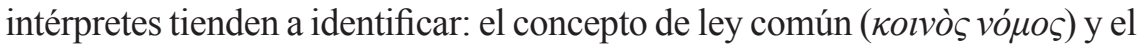
de razón común (kolvòৎ $\lambda o ́ \gamma o \varsigma)^{37}$. Cleantes mismo distingue estos conceptos

recogidas en un código legal (Boeri, 2010, pp. 90-91 y 2013, pp. 192/208-211). Encontramos más persuasiva la lectura de Boeri, porque el sabio estoico más que seguir un conjunto de prescripciones morales es capaz de determinar en cada situación precisa y particular cuál es la acción virtuosa. Boeri también contrasta su lectura con la de Mistis, quien sostiene que la ley natural no debe ser entendida como algo puramente internalista (centrada en las disposiciones del agente), argumentando que la ley natural deriva de la mente divina y, por tanto, es externamente impuesta (Mistis, 2003, p. 39). No obstante, dado que la recta razón del sabio se identifica con la divina, consideramos que debemos entender la ley natural no como algo externamente impuesto, sino como imposición de la recta razón propia. De este modo, el sabio estoico no ha de ser comprendido como un ser heterónomo, sino como uno autónomo.

36 "Est quidem vera lex recta ratio naturae congruens, diffusa in omnis, constans, sempiterna, quae vocet ad officium iubendo, vetando e fraude deterreat".

${ }^{37}$ Boeri (2013, pp. 194/207-208) afirma que los estoicos identifican la ley natural con la razón universal y por ello le confiere la función tanto de establecer el orden de toda la realidad como de prescribir las acciones correctas e incorrectas. Bénatouil (2002,

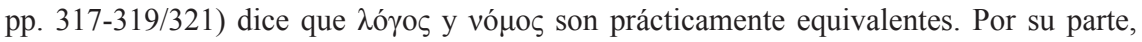

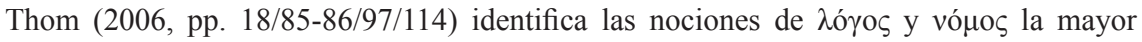
parte de su interpretación del Himno a Zeus. No obstante, hacia la página 112 de su libro, sostiene simultáneamente dos tesis que parecen opuestas: (i) afirma que el mismo $\lambda o ́ \gamma o \zeta$ que armoniza el bien con el mal es aquél que provee la norma en conformidad con la 
al interior de su Himno a Zeus, afirmando que si bien todas la cosas ocurren en conformidad con la razón común (v. 21), los malos no obedecen la ley común (v 17/24). En otras palabras, aunque los bienes y los males suceden en conformidad con la razón divina, solo las acciones buenas son conformes al deber. Si los malos, insiste Cleantes en su himno, comprendieran la racionalidad del mundo, ej. comprendieran que tanto los bienes como los males son necesarios, no tratarían de escapar a esta racionalidad huyendo de la muerte, la pobreza, la enfermedad, y buscando desesperadamente los honores, los placeres y las riquezas (v. 22-23/27-29) ${ }^{38}$. Si entendieran esta racionalidad, podrían vivir una vida en obediencia a las prohibiciones y mandatos de la recta razón, en otras palabras, llevarían una existencia conforme a la ley universal (v. 24-25).

Ahora bien, a partir de lo que hemos mencionado hasta aquí podemos ver que el fin humano en sus dos primeras formulaciones (ej. vivir en armonía y vivir virtuosamente) puede ser identificado con la vida en conformidad con la ley común. Así lo reporta Diógenes Laercio quien afirma que para los estoicos:

[e]l fin llega a ser vivir consistentemente con la naturaleza, esto es, vivir en conformidad con la naturaleza propia y la del todo, realizando ninguna de las cosas que es prohibida por la ley común, es decir, por la recta razón

cual deben actuar las personas. De este modo, parece afirmar que el $\lambda$ ó ${ }_{0} \varsigma$ tiene la misma

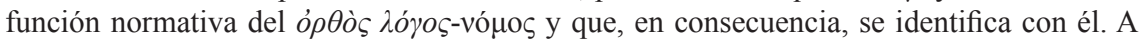
renglón seguido afirma que $\lambda$ ó $о \varsigma$ y vó $\mu$ o $\varsigma$ expresan diferentes perspectivas (racionalidad y normatividad) del mismo orden divino, con lo cual parece distinguir dos funciones de la divinidad a la manera que lo he hecho en este escrito. Una tensión semejante encontramos en la página 122. Sin seguridad de cuál es finalmente la postura defendida por Thom en este respecto, a través de este escrito buscamos distinguir con precisión las funciones atribuidas al $\lambda$ ó $о \varsigma$ y vó $\mu$ o divino para evitar estas confusiones.

${ }^{38}$ Meijer (2007, p. 221) en su interpretación del Himno a Zeus establece una distinción entre el $\lambda$ ó ${ }^{\circ} \varsigma$, descrito por él como un escenario que fija el lugar que cada entidad debe ocupar y que armoniza las acciones de los hombres buenos y los malos, y el vó $\mu$ os, que equivale a los dictados de la recta razón. No obstante, él encuentra una tensión al interpretar el v. 22 en donde se dice que los malos intentando huir ( $\varphi \varepsilon v ́ \gamma o v \tau \varepsilon \varsigma)$ de la razón común se procuran los males. De acuerdo con él, hay aquí un silencioso cambio en el significado del término $\lambda$ ó $\gamma$ s, que se debe entender ya no como escenario sino como ley, dado que uno no puede huir del escenario aunque sí puede desobedecer la ley. En mi lectura de la línea hago énfasis en que el término $\varphi \varepsilon v ́ \gamma o v \tau \varepsilon \varsigma$ expresa sólo el intento de huir de la razón divina y no el que la huida se lleve efectivamente a cabo. De este modo, no creo que haya en esta línea un desplazamiento del significado entre los términos $\lambda$ ó 
que fluye a través de todas las cosas y es idéntica con Zeus, quien es el líder de la administración de los seres. Esto mismo es la virtud del hombre feliz y el buen fluir de la vida: que todas sus acciones se den según una concordancia del daimôn de cada uno con la voluntad del administrador del todo ${ }^{39}$. (DL 88 (L\&S 63C, SVF 1.162))

Así, dado que vivir en armonía o vivir virtuosamente solo se logra cuando se lleva una vida en conformidad con la recta razón, equivalente a la ley natural o ley común, se puede afirmar que el fin de la vida humana es vivir en conformidad con esta ley. La tercera formulación del fin -ej. establecer una comunidad entre humanos y dioses- también puede ser identificada con la vida en conformidad con la ley natural. En efecto, los estoicos consideran que debido a que humanos y dioses compartimos la racionalidad y por ello estamos constituidos por naturaleza para compartir también la recta razón, todos nosotros estamos sujetos a la misma ley natural y gobernados bajo una misma concepción de la justicia (Cicerón, De leg. I. 15,42. (SVF 3.319) SVF 2.1127)). Es cierto, insisten los estoicos, que los necios ni ven ni escuchan la ley natural y que por ello cometen todo tipo de injusticias ${ }^{40}$. No obstante, su misma naturaleza determina cuál comportamiento es recto para ellos y en esa medida determina aquello que ellos deben hacer y aquello de lo que deben abstenerse. Por este motivo, de manera análoga a como nosotros consideramos a los niños como miembros de nuestra comunidad aunque aún no desempeñen las labores propias de un ciudadano, así también los hombres necios son parte de la comunidad de hombres y dioses pese a que no hayan alcanzado aún la recta razón (Diodoro Crisostomo, 36.23 (SVF 3. 334)). Es por esto que nosotros tenemos deberes para con los otros hombres aunque sean necios y no así, por ejemplo, para con los animales (Cicerón, De fin. III 20,67 (SVF 3.371)). No obstante, consideran los estoicos, el sabio es el único

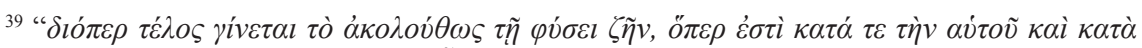

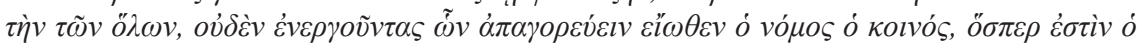

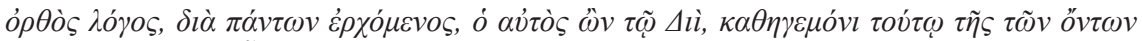

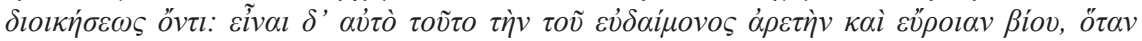

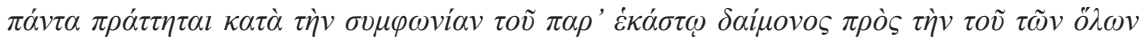

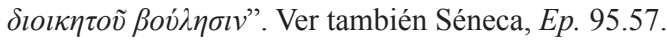

${ }^{40}$ El Himno a Zeus es una clara evidencia de que el cosmopolitismo estoico es una idea que se remite a Cleantes, y no una idea propia del estoicismo tardío. Así lo argumenta claramente Boeri (2013, p. 188), en oposición a la lectura de Julia Annas (1993, pp. 160-164 y 2007, pp. 69-70). Como sustento de esto Boeri adiciona también los siguientes pasajes: DL 7.86-89 (L\&S 57a, 63c) y Epícteto, Diss. 2. 6, 9-10.
} 
que verdaderamente puede llamarse ciudadano libre. Los necios, siendo parte de esta comunidad de manera imperfecta, no podrán ser entendidos como libres y recibirán el castigo correspondiente a su desobediencia a la ley $^{41}$. Así, el vínculo compartido por los humanos y los dioses es alcanzado plenamente cuando el humano es capaz de vivir en conformidad con los dictados de la recta razón. Solo alcanzando plenamente el desarrollo de la naturaleza humana es posible hacer del mundo esa cosmopolis imaginada por los estoicos que es gobernada rectamente bajo la misma ley natural ${ }^{42}$.

\section{Conclusión}

Con el DesarRollo De estos tRes APARTAdos esperamos haber contribuido a delimitar el papel explicativo que los estoicos atribuían a la noción de providencia, racionalidad y ley natural, y de la mano de ello a comprender mejor la teoría estoica de la constitución del mundo y las funciones que la mente divina ejerce en ella. Según lo que hemos argumentado, (i) el término providencia remite a una función de la voluntad divina, mediante la cual se establece la finalidad que ha de perseguir la conformación del mundo. (ii) El concepto de racionalidad se refiere a una función independiente de la mente divina, que es la encargada de establecer las exigencias lógicas y causales que han de ser respetadas en dicha constitución ${ }^{43}$. Estas dos funciones generaban una tensión según la cual, aunque el propósito principal de Dios es la creación del mejor mundo posible, su racionalidad exige o armoniza la existencia de males. Como elemento mediador en este conflicto, aparecen (iii) los conceptos de deber y ley natural, los cuales remiten a un aspecto normativo de la naturaleza derivado de la recta razón divina que tiene como función decretar a cada entidad el comportamiento apropiado para la consecución del fin deseado por Dios.

\footnotetext{
${ }^{41}$ Para la idea de que sólo quien sigue la recta razón es libre ver Long (1971, p. 175/n.12), Boeri (2010, pp. 90/94; 2013, p. 191/n. 22). Para la idea de castigo a quien la desobedece ver Cicerón, Rep. 3.33. Ambas ideas se encuentran presentes en DL, 7.121.

${ }^{42}$ Diodoro Crisostomo, 36.29 (SVF 2.1130); Simplico, Aris. Phys. p. 420-6 (SVF 3.339); Ario Didimo en Eusebio, praep. ev. 15.15.3-5 (L\&S 67L, SVF 2.528).

${ }^{43}$ En el contexto de esta argumentación se llegó a una importante conclusión secundaria: (ii') El concepto de destino remite a la cadena de causas producto de la conjunción entre la voluntad divina y su racionalidad.
} 


\section{Referencias}

Annas, J. (2007). Ethics in Stoic Philosophy. Phronesis, 52, pp. 58-87.

Annas, J. (1993). The Morality of Happiness. Oxford: Oxford University Press.

Aecio. (1956). De placitis reliquiae. H. Diels. (Ed.), Doxographi graeci. Berolini, Lipsiae: apud W. de Gruyter et socios.

Afrodisia, A.D. (1887). De anima libri mantissa. I. Bruns. (Ed.), Alexandri Aphrodisiensis praeter commentaria scripta minora. Commentaria in Aristotelem Graeca. Vol. suppl. 2.1. Berlin: Reimer.

Afrodisia, A.D. (1983). De Fato. R.W. Sharples. (Ed.). London: Duckworth.

Arnim, H.F.A.V. (1903). Stoicorum veterum fragmenta collegit Ioannes ab Arnim. Lipsiae: aedibus B. G. Teubneri.

BÉnAtouïL, T (2009). How Industrious can Zeus be? The Extent and Objects of Divine Activity in Stoicism. R. Salles. (Ed.), God and Cosmos in Soticism. Oxford. Oxford University Press.

BÉnAtouïL, T. (2002). Logos et Scala naturae dans le stoïcisme de Zenon et Cleanthe. Elenchos, 2, pp. 297-331.

Boeri, M. (2013). Natural Law and Wold Order in Stoicism. G. Rossi. (Ed.), Nature and the Best Life. Exploring the Natural Bases of Practical Normativity in Ancient Philosophy. Hildeseim: Georg Olms Verlag.

Boeri, M. (2010).The Cosmic City and the Stoic Conception of Rationality. G. Cornelli \& F. Lisi. (Eds.), Plato and the City. Sankt Augustin: Academia Verlag.

CAlcidio. (1962). Platonis Timaeus translatus commentarioque instructus. J.H. Waszink. (Ed.). Londres: Leiden.

Cicerón. (1959). De Legibus. G. de Plinval. (Ed.). Paris: Belles Lettres.

Cicerón. (1917). De Natura Deorum. Leipzig: Teubner.

Cicerón. (1915). De Finibus Bonorum et Malorum. Th. Schiche. (Ed.). Leipzig: Teubner.

Cicerón. (1988). De divinatione. J. Pimentel. (Ed.). De la adivinación. México: Bibliotheca scriptorum graecorum et romanorum mexicana.

Cicerón. (1889). Librorum de Re Publica. C.F.W. Mueller. (Ed.). Leipzig: Teubner. 
Clemente. (1960 y 1970). Stromata. O.S.L. Früchtel, \& U. Treu (Eds.), Clemens Alexandrinus. Vol. II, III. Berlin: Akademie Verlag.

Diodoro Crisostomo. (1940). Discourses (Vol. III). Cohoon \& Lamar. (Eds.) London: Loeb Classical Library.

Estobeo. (1885). Ioannis Stobaei anthologium (5 vols). O.H. y C. Wachsmuth (Ed.). Berlin: Weidmann.

Eusebio. (1954-1956). Preparatio evangelica. K. Mras. (Ed.). Berlin: Akademie Verlag.

Galeno. (1952). On the Natural Faculties. A. Brock. (Ed.). London: Loeb Classical Library.

Gelio. (2002). Noctes Atticae. Noches Áticas. A. Gaos (Ed.). México: Bibliotheca scriptorum graecorum et romanorum mexicana.

Gourinat, J. B. (2009). The Stoics on Matter and Prime Matter: 'Corporealism' and the Imprint of Plato's Timaeus. R. Salles. (Ed.), God and Cosmos in Soticism. Oxford: Oxford University Press.

Inwood, B. (1985). Ethics and Human Action in Early Stoicism. Oxford: Oxford University Press.

Inwood, B. \& Donini, P. (1999). Stoic Ethics. Algra et al. (Eds.), The Cambridge History of Hellenistic Philosophy. Cambridge: Cambridge University Press.

LAertius, D. (1925) [DL]. Vitae philosophorum. London: Loeb Classical Library.

Liddell, H. G., Scott, R., Jones, H.S., \& McKenzie, R. (1996). A Greek-English lexicon. Oxford/New York: Clarendon Press/Oxford University Press.

Long, A., \& Sedley, D.N. (1987). [L\&S]. The Hellenistic Philosophers. Cambridge [Cambridgeshire]/New York: Cambridge University Press.

Long, A. (1971). Freedom and Determinism in the Stoic Theory of Human Action. A. Long (Ed.), Problems in Stoicism. London: Athlone Press.

Long, A. (1968). The stoic concept of evil. The Philosophical Quarterly, 18(73), pp. 329-343.

Marcus Aurelius. (1944). M. Antonius Imperator Ad Se Ipsum. A.S.L. Farquharson. (Ed.). Oxford: Clarendon Press.

MeIJER, P. (2007). Stoic theology: Proofs for the existence of the cosmic god and of the traditional gods, including a commentary on Cleanthes' hymn on Zeus. Delft: Eburon. 
Meyer, S. (2009). Chain of Causes. What is Stoic Fate? R. Salles. (Ed.), God and Cosmos in Soticism. Oxford: Oxford University Press.

Nemesio. (1987). De Natura Hominis. M. Morani. (Ed.), Nemesii Emeseni. De natura hominis, Bibliotheca Scriptorum Graecorum et Romanorum Teubneriana. Leipzig: Teubner.

Orígenes. (1967-1969). Contra Celsum. M. Borret. (Ed.), Origène. Contre Celse. Paris: Éditions du Cerf.

Oxford Latin Dictionary. (1968). Oxford/London: Clarendon Press.

Pabón de Urbina. (2002). Diccionario Griego-Español. Barcelona: Vox

Plutarco. (1895a). De Stoicorum repugnantiis. G.N. Bernardakis. (Ed.), Moralia. VI. Leipzig: Teubner.

Plutarco. (1895b). De communibus notitiis adversus Stoicos. Moralia. VI. G.N. Bernardakis. (Ed.). Leipzig: Teubner.

Plutarco. (1889). De Iside et Osiride. G.N. Bernardakis. (Ed.), Moralia. II. Leipzig: Teubner.

Pseudoplutarco. (1959). De Fato. J. Hendreson (Ed.), Plutarch moralia. London: The Loeb classical library.

Salles, R. (2013). La razón cósmica en el estoicismo y sus raíces platónicas. Anuario filosófico, 46(1). pp. 49-57.

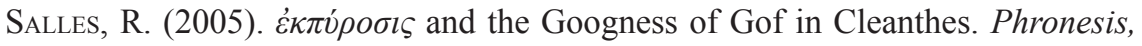
50(1), pp. 56-78.

SÉneCA. (1935). De Beneficiis. J.W. Basore. (Ed.), Moral Essays: Volume III. London/New York: Heinemann.

SÉNECA. (1917-1925). Ad Lucilium Epistulae Morales, vol. 1-3. R.M. Gummere. (Ed.). London: Loeb Classical Library

Sexto Empírico. (1914 y 1961). Adversus mathematicos. H. Mutschmann \& J. Mau. (Eds.), Sexti Empirici opera. Vols. II, III. $2^{\text {a }}$ Edición. Leipzig: Teubner.

Tном, J. (2006). Cleanthes' Hymn to Zeus. Tübingen: Mohr Siebeck. 